\section{Spin crossover in phosphorus- and arsenic-bridged cyclopentadienyl-manganese(II) dimers $\dagger$}

\author{
Sabine Scheuermayer ${ }^{a}{ }^{\text {Floriana Tuna, }}{ }^{b c}$ Michael Bodensteiner, ${ }^{a}$ Manfred Scheer ${ }^{* a}$ and \\ Richard A. Layfield $* a c$
}

Received 23rd April 2012, Accepted 11th May 2012

DOI: $10.1039 / \mathrm{c} 2 \mathrm{cc} 32893 \mathrm{c}$

Manganocene reacts with $\mathrm{LiE}\left(\mathrm{SiMe}_{3}\right)_{2}(\mathrm{E}=\mathrm{P}$ or As) to give $\left[\left(\eta^{5}-\mathrm{Cp}\right) \mathrm{Mn}\left\{\mu-\mathrm{E}\left(\mathrm{SiMe}_{3}\right)_{2}\right\}\right]_{2}$, where $\mathrm{E}=\mathrm{P}$ (1) or As (2). The temperature dependence of the magnetic susceptibility in 1 and 2 is due to antiferromagnetic exchange and to spin-crossover (SCO). Compound 2 shows two-step SCO with hysteresis, involving high-spin $(S=5 / 2)$ and intermediate-spin $S=(3 / 2) \mathrm{Mn}(\mathrm{II})$.

The high-spin/low-spin bistability of spin-crossover (SCO) transition metal complexes is a fascinating property that attracts considerable interest because of its potential applications in molecular switches. ${ }^{1}$ The largest class of SCO compounds comprises monometallic, octahedral iron(II) complexes with six $\mathrm{N}$-donor ligands, whose bistability involves interconversions of the high-spin $\left(t_{2 g}\right)^{4}\left(e_{g}\right)^{2}$ and the low-spin $\left(t_{2 g}\right)^{6}\left(e_{g}\right)^{0}$ states. $^{2}$ SCO has also been observed in five-coordinate iron(II) complexes, ${ }^{3}$ a tetrahedral iron(II) complex, ${ }^{4}$ and in monometallic complexes of chromium(II), manganese(III) and cobalt(II). ${ }^{5}$ Polymetallic, exchange-coupled SCO compounds with bridging $\mathrm{N}$-donor ligands are less common, however they are attractive synthetic targets because interactions between SCO centres could lead to significant enhancements in cooperativity and bistability properties. ${ }^{6}$ Although considerable progress has been made with $\mathrm{N}$-donor ligands, the different electronic properties of ligands based on heavier pnictogens such as phosphorus and arsenic could provide an alternative method of influencing the interplay between magnetic exchange and SCO. Thus, we now report the structures and magnetic properties of the phosphorus- and arsenic-bridged cyclopentadienyl-manganese(II) dimers $\left[\mathrm{CpMn}\left\{\mu-\mathrm{E}\left(\mathrm{SiMe}_{3}\right)_{2}\right\}\right]_{2}$, with $\mathrm{E}=\mathrm{P}$ (1) or As (2). In $\mathbf{1}$ and 2, antiferromagnetic exchange occurs concurrently with thermally induced two-step SCO involving the high-spin $S=5 / 2$ and the rare intermediate-spin $S=3 / 2$ states of manganese(II).

\footnotetext{
${ }^{a}$ Institut für Anorganische Chemie, Universität Regensburg, 93040 Regensburg, Germany.

E-mail: Manfred.Scheer@chemie.uni-regensburg.de

${ }^{b}$ EPSRC National UK EPR Facility, Photon Science Institute,

The University of Manchester, Oxford Road, Manchester, M13 9PL, UK

${ }^{c}$ School of Chemistry, The University of Manchester, Oxford Road, Manchester, M13 9PL, UK.

E-mail: Richard.Layfield@manchester.ac.uk

$\dagger$ Electronic supplementary information (ESI) available: CCDC reference codes 863319-863320 for $\mathbf{1}$ and 2. Details of synthesis and
} crystallography. See DOI: $10.1039 / \mathrm{c} 2 \mathrm{cc} 32893 \mathrm{c}$

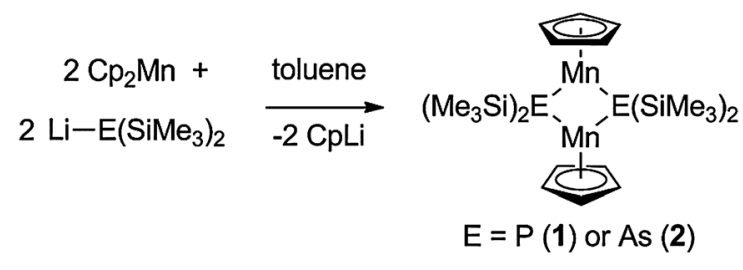

Scheme 1 Synthesis of 1 and 2.

Compounds 1 and 2 were synthesized by reacting $\mathrm{Cp}_{2} \mathrm{Mn}$ with $\mathrm{LiE}\left(\mathrm{SiMe}_{3}\right)_{2}(\mathrm{E}=\mathrm{P}, \mathrm{As})($ Scheme 1). The structures of 1 and $\mathbf{2}$ were determined by $\mathrm{X}$-ray diffraction, $\dagger$ and are very similar, both consisting of pnictogen-bridged dimers of general formula $\left[\left(\eta^{5}-\mathrm{Cp}\right) \mathrm{Mn}\left\{\mu-\mathrm{E}\left(\mathrm{SiMe}_{3}\right)_{2}\right\}\right]_{2}$. The dimers have approximate molecular $D_{2 \mathrm{~h}}$ symmetry, and the $\left\{\mathrm{CpME}_{2}\right\}$ coordination environments have approximate $C_{2 \mathrm{v}}$ symmetry. Assuming that an $\eta^{5}-\mathrm{Cp}$ ligand formally occupies three coordination sites, each metal atom in $\mathbf{1}$ and $\mathbf{2}$ is five-coordinate.

The formally five-coordinate, 15-valence-electron phosphidebridged dimanganese compound $\left[\mathrm{CpMn}\left\{\mu-\mathrm{P}\left(\mathrm{SiMe}_{3}\right)_{2}\right\}\right]_{2}$ (1) crystallizes with two independent molecules in the unit cell, $\mathbf{1 a}$ and $\mathbf{1 b}$, which are structurally similar and lie about independent inversion centres (Fig. 1, S1). In 1a, the two Mn(II) centres are bridged by two $\mu-\left[\left(\mathrm{Me}_{3} \mathrm{Si}\right)_{2} \mathrm{P}\right]^{-}$ligands. The $\mathrm{Mn}(1)-\mathrm{P}(1)$ and $\mathrm{Mn}(1)-\mathrm{P}(1 \mathrm{~A})$ bond distances in 1a are 2.5075(5) and 2.5123(5) $\AA$ and the P-Mn-P and $\mathrm{Mn}-\mathrm{P}-\mathrm{Mn}$ angles are $93.83(2)$ and $86.17(2)^{\circ}$, respectively. The arsenide-bridged dimanganese compound $\mathbf{2}$ has only one independent molecule in the unit cell, which lies about an inversion centre (Fig. 1). The $\mathrm{Mn}-\mathrm{As}$ bond distances in $\mathbf{2}$ are 2.5877(7) and 2.5980(8) $\AA$, and the As-Mn-As and Mn-As-Mn angles of 90.81(2) and $89.20(2)^{\circ}$, respectively,
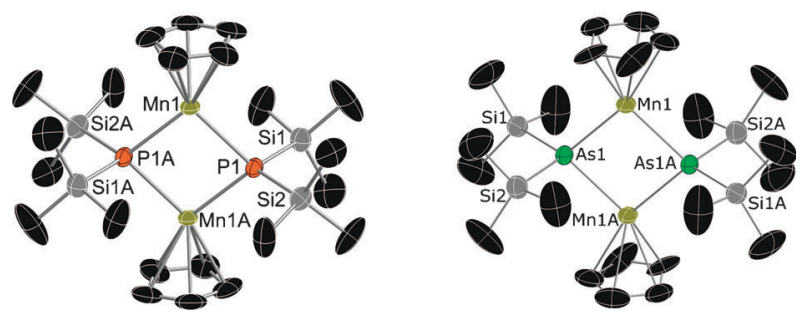

Fig. 1 Thermal ellipsoid plots (30\% probability) of the molecular structures of 1a and 2. Hydrogen atoms not shown. Symmetry transformation for equivalent atoms: $(-x,-y,-z)$. 
Table 1 Selected interatomic distances and bond angles for $\mathbf{1 a}$ and 2

\begin{tabular}{lll}
\hline & 1a & $\mathbf{2}$ \\
\hline $\mathrm{Mn}-\mathrm{E}$ & $2.5075(5), 2.5123(5)$ & $2.5877(7), 2.5980(8)$ \\
$\mathrm{Mn}-\mathrm{C}$ & $2.326(19)-2.47(2)$ & $2.29(3)-2.47(2)$ \\
$\mathrm{Mn} \cdots \mathrm{Mn}^{a}$ & $3.429(2)$ & $3.641(1)$ \\
$\mathrm{Mn} \cdots \mathrm{Mn}^{b}$ & $8.6541(5)$ & $8.7884(8)$ \\
$\mathrm{E}-\mathrm{Mn}-\mathrm{E}$ & $93.83(2)$ & $90.81(2)$ \\
$\mathrm{Mn}-\mathrm{E}-\mathrm{Mn}$ & $86.17(2)$ & $89.20(2)$ \\
${ }^{a}$ Intramolecular distance. & ${ }^{b}$ Shortest intermolecular distance. \\
\hline
\end{tabular}

indicate a square $\mathrm{Mn}_{2} \mathrm{As}_{2}$ unit. The $\mathrm{Mn}-\mathrm{C}$ distances to the $\eta^{5}$ $\mathrm{Cp}$ ligands in 1a, $\mathbf{1 b}$ and $\mathbf{2}$ are in the range 2.326(19)-2.47(2) (average $2.405 \AA$ ), 2.365(14)-2.437(16) (average $2.400 \AA$ ), and 2.29(3)-2.46(4) $\AA$ (average $2.38 \AA$ ), respectively, and hence are similar to those found in high-spin manganese(II) cyclopentadienides. $^{7}$ The $\mathbf{M n} \cdot \cdots$ Mn distances in $\mathbf{1 a}, \mathbf{1 b}$ and $\mathbf{2}$ are 3.429(2), 3.431(2) and 3.641(1) ̊, respectively (Tables 1, S2). Since the range of manganese-manganese bond lengths in the CSD is $2.170-3.291 \AA$ (average $2.843 \AA$ ), ${ }^{8}$ it is unlikely that such bonding occurs in $\mathbf{1}$ and $\mathbf{2}$.

Magnetic susceptibility measurements on polycrystalline samples of $\mathbf{1}$ and $\mathbf{2}$ were carried out in the temperature range $2-300 \mathrm{~K}$ in an applied field of $1000 \mathrm{G}$. For the phosphidebridged dimanganese(II) compound 1, $\chi_{\mathrm{M}} T$ decreases monotonically from $5.71 \mathrm{~cm}^{3} \mathrm{~K} \mathrm{~mol}^{-1}$ at $300 \mathrm{~K}$ to $0.027 \mathrm{~cm}^{3} \mathrm{~K} \mathrm{~mol}^{-1}$ at $2 \mathrm{~K}$ (Fig. 2). The value of $\chi_{\mathrm{M}} T$ at $300 \mathrm{~K}$ is about seventy-five per-cent of the predicted value of $8.75 \mathrm{~cm}^{3} \mathrm{~K} \mathrm{~mol}^{-1}$ for two $S=5 / 2$ manganese(II) ions, and the very small value of $\chi_{\mathrm{M}} T$ at $2 \mathrm{~K}$ implies that dimers of $\mathbf{1}$ essentially occupy a diamagnetic ground state. The diamagnetic ground state of $\mathbf{1}$ at $2 \mathrm{~K}$ is most likely due to antiferromagnetic exchange.

Somewhat unexpectedly, although the temperature dependence of $\chi_{\mathrm{M}} T$ in 1 appears to indicate antiferromagnetic exchange, the susceptibility data could not be fitted with the Heisenberg-Dirac-Van-Vleck (HDVV) model across the full temperature range of $2-300 \mathrm{~K}$. Rather, at temperatures greater than approximately $210 \mathrm{~K}$ the $\chi_{\mathrm{M}} T$ vs. $T$ graph could be modelled quite well using the spin Hamiltonian formalism $H=-2 J\left(S_{\mathrm{MnA}} \cdot S_{\mathrm{MnB}}\right)$, where $S_{\mathrm{MnA}}$ and $S_{\mathrm{MnB}}$ refer to the spin of the two Mn(II) ions in each dimer. This model enabled

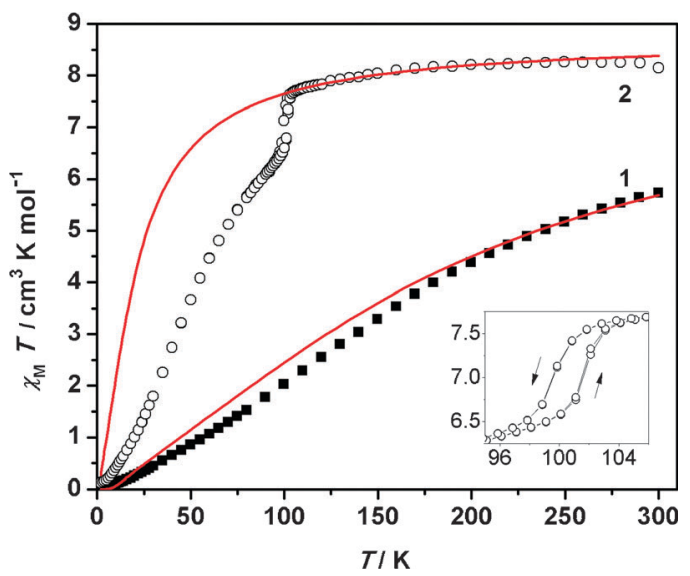

Fig. $2 \chi_{\mathrm{M}} T$ vs. $T$ plots for $\mathbf{1}$ (squares) and $\mathbf{2}$ (circles). The red lines are a theoretical fit of the experimental data to a simple isotropic exchange model (see text for parameters). Inset: hysteresis loop for $\mathbf{2}$. a coupling constant of $J=-13.5 \mathrm{~cm}^{-1}$ to be extracted using $g=2$ and $S_{\mathrm{Mn}}=5 / 2$. However, below $210 \mathrm{~K}$, the theoretical model over-estimates the experimental value of $\chi_{\mathrm{M}} T$, until the diamagnetic ground state is reached at $2 \mathrm{~K}$. The discrepancy could indicate a spin crossover to a lower spin state of manganese(II), although the increasingly pronounced effects of magnetic exchange preclude any quantitative conclusions.

The temperature dependence of $\chi_{\mathrm{M}} T$ in the arsenide-bridged dimanganese(II) compound $\mathbf{2}$ is particularly unusual (Fig. 2). Thus, $\chi_{\mathrm{M}} T$ at $300 \mathrm{~K}$ is $8.20 \mathrm{~cm}^{3} \mathrm{~K} \mathrm{~mol}^{-1}$, which is only slightly less than the predicted value for two uncoupled $S=5 / 2$ manganese(II) ions. The value of $\chi_{\mathrm{M}} T$ then decreases slowly to reach $7.67 \mathrm{~cm}^{3} \mathrm{~K} \mathrm{~mol}^{-1}$ at $105 \mathrm{~K}$, and then abruptly to reach $6.37 \mathrm{~cm}^{3} \mathrm{~K} \mathrm{~mol}^{-1}$ at $96 \mathrm{~K}$. Below $96 \mathrm{~K}, \chi_{\mathrm{M}} T$ does not plateau but instead continues to decrease steadily, and then decreases more rapidly below $75 \mathrm{~K}$ to reach $0.12 \mathrm{~cm}^{3} \mathrm{~K} \mathrm{~mol}^{-1}$ at $2 \mathrm{~K}$. The small value of $\chi_{\mathrm{M}} T$ at $2 \mathrm{~K}$ indicates that dimers of 2 also occupy an essentially diamagnetic ground state. Subsequent warming from $2 \mathrm{~K}$ to $300 \mathrm{~K}$ produced a small hysteresis loop between 96 and $105 \mathrm{~K}$, which remained unchanged during several subsequent cooling-warming cycles at the temperature sweep rate of $2 \mathrm{~K}$ per minute.

In 2 , above $105 \mathrm{~K}$ the susceptibility data could be fitted with the same HDVV model applied to $\mathbf{1}$, which corresponds to a dimer with two high-spin (HS, $S_{\mathrm{Mn}}=5 / 2$ ) $\mathrm{Mn}$ (II) ions with $g=2$. From this model, very weak antiferromagnetic exchange was identified, with $J=-1.5 \mathrm{~cm}^{-1}$. The model substantially overestimates $\chi_{\mathrm{M}} T$ below $105 \mathrm{~K}$ until the diamagnetic ground state is reached at $2 \mathrm{~K}$. The sharp decrease in $\chi_{\mathrm{M}} T$ and the associated hysteresis loop when $T=96-105 \mathrm{~K}$ strongly suggest that a spin crossover has occurred. Furthermore, the value of $\chi_{\mathrm{M}} T$ at $96 \mathrm{~K}$ is approximately eighty per cent of the average value of $\chi_{\mathrm{M}} T$ above $105 \mathrm{~K}$, which is consistent with a dimer that contains one HS manganese(II) and one intermediate-spin manganese(II) $\left(\mathrm{IS}, S_{\mathrm{Mn}}=3 / 2\right)$, i.e. 2 - $\left[\mathrm{HS}_{\mathrm{MnA}}-\mathrm{IS}_{\mathrm{MnB}}\right]$ and/or 2 -[ $\left.\mathrm{IS}_{\mathrm{MnA}}-\mathrm{HS}_{\mathrm{MnB}}\right]$. A simple d-orbital splitting diagram that illustrates the SCO process is shown in Fig. 3. The diamagnetism of 2 at $2 \mathrm{~K}$ can only be accounted for by an exchange-coupled dimer in which $S_{\mathrm{MnA}}=S_{\mathrm{MnB}}$, therefore at least one more SCO must occur below $96 \mathrm{~K}$. The species that is most likely to form at $2 \mathrm{~K}$ is therefore 2-[IS $\left.\mathrm{MnA}-\mathrm{IS}_{\mathrm{MnB}}\right]$ as a result of a thermally induced, two-step SCO.

Insight into the temperature dependence of $\chi_{\mathrm{M}} T$ in $\mathbf{1}$ can be obtained from a consideration of the magnetic susceptibility of $\mathbf{2}$.

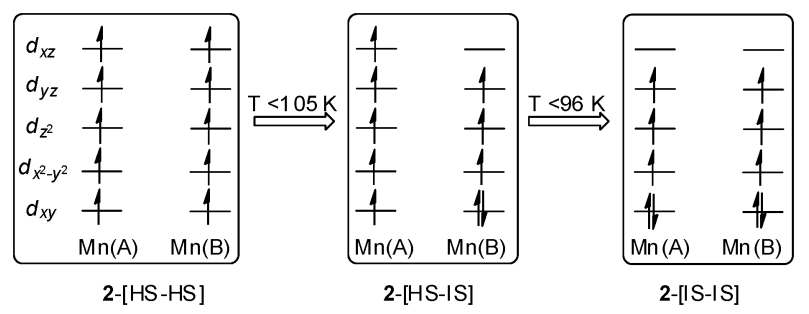

Fig. 3 Qualitative d-orbital splitting diagram and two-step spin-crossover process for the $\left\{\mathrm{CpMnAs}_{2}\right\}$ units in $\mathbf{2}$ in $C_{2 \mathrm{v}}$ symmetry. The axes are centred on manganese: the $y$-axis is assumed to be perpendicular to the $\mathrm{MnAs}_{2}$ plane and the $z$-axis coincides with the $\mathrm{Cp}-\mathrm{Mn}$ axis. 
For 1 at $300 \mathrm{~K}, \chi_{\mathrm{M}} T=5.71 \mathrm{~cm}^{3} \mathrm{~K} \mathrm{~mol}^{-1}$, which is similar to the value of $\chi_{\mathrm{M}} T=6.37 \mathrm{~cm}^{3} \mathrm{~K} \mathrm{~mol}^{-1}$ for 2 at $96 \mathrm{~K}$. This observation on 1 can be accounted for either by antiferromagnetic exchange or by SCO to 1-[HS-IS]; the former seems more likely because the susceptibility data above $250 \mathrm{~K}$ are reproduced well by a simple isotropic exchange model. The lower-than-predicted value of $\chi_{\mathrm{M}} T$ in $\mathbf{1}$ is most likely due to magnetic exchange, which is almost an order of magnitude stronger than the arsenic-mediated exchange in $\mathbf{2}$. The most likely explanation for the different $J$-values is that the P-donor ligands in $\mathbf{1}$ exert a stronger ligand field than the As-donors in 2, although the slightly different bridging angles may also influence the exchange. The continued, more-gradual decrease in $\chi_{\mathrm{M}} T$ with temperature in $\mathbf{1}$ can thus be assigned to antiferromagnetic exchange and/or SCO to lower-spin states of the manganese(II) ions. As discussed above, direct manganesemanganese bonding can be discounted because the separation of the atoms is too large; $c f$. the $\mathrm{Mn}-\mathrm{Mn}$ single bond of 2.8717(4) $\AA$ in the diamagnetic dimer $\left[\mathrm{CpMn}\left(\mathrm{PH}_{2} \mathrm{Ph}\right)(\mu-\mathrm{P}(\mathrm{H}) \mathrm{Ph}\}\right]_{2}$, which is $0.55 \AA$ shorter than the $\mathrm{Mn} \cdots \mathrm{Mn}$ separation in 1 . $^{9}$ Forms of 1 and 2 containing low-spin manganese(II) (LS, $S_{\mathrm{Mn}}=1 / 2$ ) are unlikely, however this possibility cannot be entirely discounted solely on the basis of magnetic susceptibility measurements.

To the best of our knowledge, exchange coupling constants for ligands in which the bridging atom is either phosphorus or arsenic have not previously been determined experimentally. In the few instances where the magnetic properties of heavypnictogen-bridged manganese(II) compounds have been studied, only the effective magnetic moments were reported. ${ }^{10}$ One exception is the penta-manganese(II) cage $\left[\mathrm{Mn}_{5}\left\{\mathrm{~N}\left(\mathrm{SiMe}_{3}\right)_{2}\right\}-\right.$ $\left.\left\{\mu_{4}-\mathrm{PSi}^{i} \mathrm{Pr}_{3}\right\}_{2}\left\{\mu-\mathrm{P}(\mathrm{H}) \mathrm{Si}^{i} \mathrm{Pr}_{3}\right\}_{5}\right]$, where anti-ferromagnetic exchange with $J$-values up to $-220 \mathrm{~cm}^{-1}\left(H=-J \cdot S_{\mathrm{A}} \cdot S_{\mathrm{B}}\right)$ were determined using quantum chemical methods. ${ }^{11}$ Compounds $\mathbf{1}$ and $\mathbf{2}$ differ from existing SCO materials, firstly because they contain manganese(II), and secondly because they are the first to undergo electronic structure changes to and from an intermediate spin state. Although mixed high-spin, intermediate-spin iron(III) porphyrin complexes are known, such compounds exist as quantum mechanical admixtures of spin states via spin-orbit coupling. $^{12}$

Whereas SCO in "classical" manganese(II) coordination complexes is also rare, several manganocenes do show spin equilibria. ${ }^{13,14}$ For example, crystalline $1,1^{\prime}$-dimethylmanganocene has a temperature-dependent effective magnetic moment that decreases gradually from $4.41 \mu_{\mathrm{B}}$ at $328 \mathrm{~K}$ to $3.71 \mu_{\mathrm{B}}$ at $196 \mathrm{~K} .{ }^{13}$ Gradual SCO from a high-spin to an intermediate-spin configuration has also been proposed to account for the temperature dependence of $\mu_{\mathrm{eff}}$ in the manganese(II) allyl $\left[\mathrm{Mn}\left\{1,3-\left(\mathrm{Me}_{3} \mathrm{Si}\right)_{2} \mathrm{C}_{3} \mathrm{H}_{3}\right\}_{3}\right]^{-}$and in compounds containing the $\left[\left(\eta^{2}-\mathrm{Cp}\right)_{3} \mathrm{Mn}\right]^{-}$anion. ${ }^{15}$ Compound $\mathbf{2}$ is therefore the first twostep SCO compound of manganese(II), and it is unique because the first SCO transition is sharp and, in contrast to all other manganese(II) SCO compounds, shows hysteresis.

In summary, the antiferromagnetically coupled dimers $\mathbf{1}$ and $\mathbf{2}$ are spin-crossover materials. The coupling constant of $J=-13.5 \mathrm{~cm}^{-1}$ in $\mathbf{1}$ reveals that the exchange is much stronger than that in 2 , which has $J=-1.5 \mathrm{~cm}^{-1}$. SCO in 2 occurs in two steps and shows hysteresis, and was assigned to the conversion of $\mathbf{2}$-[HS-HS] into $\mathbf{2}$-[HS-IS], and then into 2-[IS-IS]. Compounds $\mathbf{1}$ and $\mathbf{2}$ demonstrate that manganese(II) has untapped potential in the development of SCO materials, and that organometallic and heavy-pnictogen ligand environments have unique attributes that could be used to control spin transitions in new ways.

\section{Notes and references}

1 (a) S. Venkataramani, U. Jana, M. Dommaschk, F. D. Sönnichsen, F. Tuczek and R. Herges, Science, 2011, 331, 445; (b) Spin Crossover in Transition Metal Compounds, Top. Curr. Chem., ed. P. Gütlich and H. A. Goodwin, Springer-Verlag, Berlin, 2004.

2 (a) C. M. Munoz and J. A. Real, Coord. Chem. Rev., 2011, 255, 2068; (b) I. A. Gass, S. R. Batten, C. M. Forsyth, B. Moubaraki, C. J. Schneider and K. S. Murray, Coord. Chem. Rev., 2011, 255, 2058; (c) J. Olguin and S. Brooker, Coord. Chem. Rev., 2011, 255, 203; (d) M. A. Halcrow, Coord. Chem. Rev., 2009, 253, 2493; (e) M. A. Halcrow, Polyhedron, 2007, 26, 3523 .

3 (a) J. Li, R. L. Lord, B. C. Noll, M.-H. Baik, C. E. Schulz and R. Scheidt, Angew. Chem., Int. Ed., 2008, 47, 10144; (b) M. Bacci, S. Midollini, P. Stoppioni and L. Sacconi, Inorg. Chem., 1973, 12, 1801.

4 J. J. Scepaniak, T. D. Harris, C. S. Vogel, J. Sutter, K. Meyer and J. M. Smith, J. Am. Chem. Soc., 2011, 133, 3824.

5 (a) S. Hayami, Y. Komatsu, T. Shimizu, H. Kamihata and Y. H. Lee, Coord. Chem. Rev., 2011, 255, 1981; (b) C. Ni, J. C. Fettinger, G. J. Long and P. P. Power, Inorg. Chem., 2009, 48, 2443; (c) D. M. Jenkins and J. C. Peters, J. Am. Chem. Soc., 2005, 127, 7148; (d) H. A. Goodwin, Top. Curr. Chem., 2004, 234, 23; (e) Y. Garcia and P. Gütlich, Top. Curr. Chem., 2004, 234, 49; $(f)$ D. M. Jenkins and J. C. Peters, J. Am. Chem. Soc., 2003, 125, 11162.

6 Selected recent examples: (a) R.-J. Wei, Q. Huo, J. Tao, R.-B. Huang and L.-S. Zheng, Angew. Chem., Int. Ed., 2011, 50, 8940; (b) B. Schneider, S. Demeshko, S. Dechert and F. Meyer, Angew. Chem., Int. Ed., 2010, 49, 9274; (c) D.-Y. Wu, O. Sato, Y. Einaga and C.-Y. Duan, Angew. Chem., Int. Ed., 2009, 48, 1475; (d) M. Nihei, M. Ui, M. Yokota, L. Han, A. Maeda, H. Kishida, H. Okamoto and H. Oshio, Angew. Chem., Int. Ed., 2005, 44, 6484.

7 R. A. Layfield, Chem. Soc. Rev., 2008, 37, 1098.

8 (a) F. H. Allen, Acta Crystallogr., Sect. B: Struct. Sci., 2002, $\mathbf{5 8}, 380$.

9 F. A. Stokes, R. J. Less, J. Haywood, R. L. Melen, R. I. Thompson, A. E. H. Wheatley and D. S. Wright, Organometallics, 2012, 31, 23.

10 (a) S. C. Goel, M. Y. Chian, D. J. Rauscher and W. E. Buhro, J. Am. Chem. Soc., 1993, 115, 160; (b) H. Chen, M. Olmstead, D. C. Pestana and P. P. Power, Inorg. Chem., 1991, 30, 1783; (c) R. A. Jones, S. U. Koschmieder and C. M. Nunn, Inorg. Chem., 1988, 27, 4524.

11 C. von Hänisch, F. Weigand and R. Clérac, Inorg. Chem., 2008, 47, 1460 .

12 M. Nakamura, Coord. Chem. Rev., 2006, 250, 2271.

13 L. T. Reynolds and G. Wilkinson, J. Inorg. Nucl. Chem., 1959, 9, 86 .

14 M. D. Walter, C. D. Sofield, C. H. Booth and R. A. Andersen, Organometallics, 2009, 28, 2005.

15 (a) C. S. Alvarez, A. Bashall, R. A. Layfield, E. J. L. McInnes, M. McPartlin, R. A. Mole, J. M. Rawson and D. S. Wright, Chem.-Eur. J., 2006, 12, 3053; (b) R. A. Layfield and S. M. Humphrey, Angew. Chem., Int. Ed., 2004, 43, 3067; (c) A. D. Bond, R. A. Layfield, J. A. MacAllister, M. McPartlin, J. M. Rawson and D. S. Wright, Chem. Commun., 2001, 1956. 